\title{
Questões de sexualidade masculina na atenção primária à saúde: gênero e medicalizaçāo"
}

Thiago Félix Pinheiro ${ }^{1}$

Márcia Thereza Couto ${ }^{2}$

Geórgia Sibele Nogueira da Silva ${ }^{3}$

PINHEIRO, T.F.; COUTO, M.T.; NOGUEIRA DA SILVA, G.S. Issues of male sexuality in primary health care: gender and medicalization. Interface - Comunic., Saude, Educ., v.15, n.38, p.845-58, jul./set. 2011.

Following the direction of masculinity studies, this paper presents an ethnographic investigation on the approach to male sexuality taken at two primary healthcare units in Natal, Rio Grande do Norte. The objective was to comprehend how the sexuality of male users of the facilities is presented within the care context and how the demands that arise within this context are addressed. In interviews with users and observations of day-to-day activities in the units, sexually transmitted infections, prostate cancer prevention and erectile problems stood out as major problems. There was an abbreviated superficial professional approach, grounded in the parameter of medicalization. Although some users accept the medical discourse and submit themselves to medicalization, it is possible to identify signs of resistance. This paper discusses how the insignias of gender not only can create barriers in healthcare, but also can lead to construction of dialogical relations between professionals and male users.

Keywords: Male sexuality. Masculinity. Medicalization. Primary Healthcare.
Este artigo apresenta pesquisa etnográfica a respeito da abordagem da sexualidade masculina em dois serviços de atenção primária à saúde em Natal/Rio Grande do Norte, Brasil. Seu objetivo é compreender como a sexualidade dos homens usuários dos serviços se apresenta no contexto da assistência, e como as demandas que se configuram nesse âmbito são abordadas. Em entrevistas com usuários e observações do cotidiano dos serviços, destacam-se, como principais problemas: as infecções sexualmente transmissíveis, a prevenção de câncer de próstata e os problemas relativos à ereção. Observa-se uma abordagem profissional superficial, abreviada e ancorada no parâmetro da medicalização. Embora alguns usuários incorporem o discurso médico e se sujeitem à medicalização, é possível identificar sinais de resistência. Discute-se como as insígnias de gênero podem, para além de marcar barreiras na assistência à saúde, provocar a construção de relações dialógicas entre profissionais e usuários homens.

Palavras-chave: Sexualidade masculina. Masculinidade. Medicalização. Atenção primária à saúde.
"Elaborado com base em Pinheiro (2010); pesquisa financiada pelo Conselho Nacional de Desenvolvimento Científico e Tecnológico (CNPq), submetida e aprovada pela Comissão de Ética para Análise de Projetos de Pesquisa (CAPPesq) da Diretoria Clínica do Hospital das Clínicas e da Faculdade de Medicina da

Universidade de São Paulo. A pesquisa multicêntrica da qual o trabalho faz parte também foi aprovada pelo Comitê de Ética em Pesquisa da instituição proponente, a

Universidade Federal de São Paulo.

1,2 Departamento de Medicina Preventiva, Faculdade de Medicina, Universidade de São Paulo. Av. Dr. Arnaldo, $455,2^{\circ}$ andar, sala 2177 , Cerqueira César. São Paulo, SP, Brasil. 01.246-903. thiagopinheiro@ hotmail.com

${ }^{3}$ Departamento de Psicologia, Universidade Federal do Rio Grande do Norte. 


\section{Introdução}

Com o intuito de discutir a abordagem da sexualidade masculina na Atenção Primária à Saúde (APS), o presente artigo problematiza as configurações da relação entre homens e profissionais-serviços de saúde a partir de questões da sexualidade e dos delineamentos que elas assumem nesse contexto.

O percurso que segue se ancora na articulação de algumas noções teóricas. A primeira é o conceito de gênero como um princípio ordenador e normatizador de práticas sociais, construído em função das condições que histórica e socialmente estabelecem as relações sociais de sexo, permeadas pelo poder e desigualdade (Scott, 1995). A segunda é a ideia de medicalização, compreendida como o processo de expansão progressiva do campo de intervenção da biomedicina por meio da redefinição de experiências e comportamentos humanos como se fossem problemas médicos (Tesser, 2006). E, finalmente, utilizase a noção de sexualidade como referência aos aspectos da vida sexual, atentando-se, contudo, para o fato de que a sexualidade diz respeito à produção de conhecimento sobre as práticas sexuais, historicamente inscrita no campo biomédico e no próprio processo de medicalização (Foucault, 2007).

\section{Homens e masculinidades na saúde}

O lugar ocupado pelos homens na produção de conhecimento em saúde tem se configurado de modo paradoxal ao longo do tempo. De certo modo, eles sempre estiveram no foco da maioria dos estudos da área, mas foram tomados, quase sempre, como parâmetro da humanidade; o homem como equivalente a ser humano (Kimmel, 1992). Essa perspectiva pouco se aproxima dos homens como sujeitos concretos, inseridos em contextos socioculturais determinados pelo gênero e outros atributos (classe, raça/etnia, geração etc.) que, postos em relação, são produtores de diferentes construções e vivências de masculinidades (Connell, 1997).

A partir da década de 1990, os homens passaram a ser abordados como segmento populacional do sexo masculino nas investigações dos padrões de morbimortalidade que consideravam a diferenciação sexual nos indicadores epidemiológicos (ver, por exemplo, Laurenti, Mello Jorge, Gotlieb, 2005).

Nas duas últimas décadas, os homens têm sido estudados com base na perspectiva de gênero, que oferece abordagem mais contextualizada com a construção social das masculinidades. Essa perspectiva, para além da construção social de gênero, engloba a dimensão relacional e de poder (Scott, 1995). É tributária dos estudos de vertente feminista - estabelece-se na crítica às desigualdades de gênero, à naturalização dos comportamentos e à medicalização dos corpos - e fortemente influenciada pelo movimento gay que, desde a década de 1970, chamava a atenção para a opressão a que os homens homossexuais eram submetidos por contrariarem os padrões de gênero estabelecidos socialmente (Arilha, 2005).

No campo da saúde, atentou-se para a influência da construção social das masculinidades na produção de comportamentos de risco à saúde e em dificuldades relacionadas à prática do cuidado (Courtenay, 2000). Somadas a isso, nas políticas públicas de saúde e na estrutura organizacional dos serviços, tornaram-se visíveis desigualdades que comprometem a relação dos homens com os serviços e o cuidado em saúde (Couto et al., 2010; Figueiredo, 2005).

Essas diferenças têm sido investigadas, especialmente, na APS, modalidade assistencial que, nos moldes da Estratégia de Saúde da Família (ESF), propõe-se a ser porta de entrada do sistema público de saúde e estratégia para a reorientação do modelo de atenção.

Embora os serviços da APS sejam apresentados como a opção da rede pública mais procurada por homens e mulheres para o cuidado em saúde (Pinheiro et al., 2002), a presença dos homens nesses espaços é sempre inferior à das mulheres, que configuram a clientela prioritária de tais serviços, assim como crianças e, mais recentemente, idosos (Figueiredo, 2005).

Nesse sentido, ocorre em tais espaços uma invisibilidade dos homens: como alvo de intervenção em saúde, expressa sobretudo na falta de programas e atendimentos direcionados aos homens; como usuários, que têm dificuldades para acessar os serviços ou para serem acolhidos com suas demandas; e como sujeitos de cuidado, que, pela expectativa dos profissionais de que o homem não cuida de si 
nem de outras pessoas, não são estimulados às práticas de prevenção e promoção de saúde (Couto et al., 2010).

A vida sexual se destaca, no cenário dos estudos orientados pela perspectiva de gênero, como um dos pilares da construção do masculino e como esfera na qual, especialmente, se expressam os valores hegemônicos de masculinidade, representados pela virilidade, potência e dominação, e ancorados na 'naturalização' de uma sexualidade instintiva, incontrolável e mais acentuada que a feminina. $O$ exercício sexual, orientado por tais valores, frequentemente, é associado ao não-cuidado em saúde e ao comportamento desprotegido em relação a si mesmo e aos outros (Gomes, 2008; Silva, 2007).

Dado que as questões de saúde sexual e reprodutiva são reconhecidamente relacionais, a sexualidade masculina passou a configurar um tema de relevância para os estudos e intervenções no campo da saúde pública. Nesse sentido, essa temática emergiu do silêncio no qual estava imersa até a década de 1980, quando, frente à epidemia da aids, os homens foram inseridos nas discussões da área (Portella et al., 2004).

Essa inserção, segundo Arilha (2005), tem sido feita tomando-se por base a ideia de que os homens são sujeitos capazes de atuar com facilidade no campo das escolhas sexuais e reprodutivas, e detentores de um poder uníssono. Essa crença está presente nos documentos de conferências da ONU. Ao mesmo tempo, os debates feitos nessas conferências buscam democratizar as relações de gênero a partir do incentivo da 'educação' dos homens para a participação nas tarefas domésticas, no âmbito da paternidade e no contexto das práticas sexuais.

Na produção científica sobre os homens na área da saúde pública, a sexualidade masculina é um dos temas que se destacam. Entretanto, esse tema é discutido com base nos seguintes núcleos de sentido: sexualidade infectante (sustentado pela maior participação dos homens nos perfis epidemiológicos das Infecções Sexualmente Transmissíveis/IST ou pelo envolvimento dos homens com a prostituição), heterossexualidade e não-monogamia (Gomes, Nascimento, 2006).

No âmbito das intervenções em saúde, diferentemente da sexualidade feminina, que, pela via da medicalização, foi tomada como objeto de um intenso controle, a sexualidade masculina tem se limitado a abordagens pontuais em situações de infertilidade, IST ou início de envelhecimento. Essas abordagens têm ocorrido, preferencialmente, nas consultas com o clínico geral, a partir de uma evocação de problemas sexuais (Bozon, 2004).

A concepção de 'disfunção sexual', que entrou em cena com o advento do Viagra ${ }^{\circledR}$, marca a superação das interpretações místicas acerca da então 'impotência sexual' e da abordagem psicológica desse problema pela explicação puramente orgânica e pela exclusividade do tratamento medicamentoso. A sexualidade, nessa transição, passou a ser pensada sob perspectiva mecânica, dissociada da parceria e emancipada do declínio inerente ao envelhecimento (Sohn, 2008). Nesse percurso, parece ter começado a ganhar força um processo de medicalização do corpo e da vida sexual dos homens, expresso, como lembra Aquino (2005), na grande produção de pesquisas e publicações (incentivadas pela indústria farmacêutica) a respeito de tal disfunção, assim como da ejaculação precoce e da reposição hormonal para o tratamento da andropausa ou climatério masculino.

Consoante a essa discussão, neste artigo, analisa-se como, no contexto de serviços de APS organizados segundo a ESF, apresentam-se questões relativas à sexualidade masculina e as possibilidades de sua abordagem pelos profissionais desses espaços. De forma mais específica, são apresentados, como temas que se destacam nessa abordagem: as IST, a prevenção de câncer de próstata e os problemas relativos à ereção.

\section{Aspectos metodológicos}

Este trabalho decorre de uma pesquisa multicêntrica voltada à investigação da relação entre homens e serviços de saúde em quatro estados brasileiros: PE, RJ, RN, SP (Couto et al., 2009). A pesquisa foi orientada pela perspectiva etnográfica, que tem longa tradição na antropologia e dispõe, como pressuposto fundante, da interpretação dos aspectos simbólicos e culturais nos contextos sociais em que ocorrem (Peirano, 1995). 
O recorte empírico para este trabalho se detém na investigação de duas Unidades Básicas de Saúde (UBS) da cidade de Natal/RN, ocorrida entre agosto de 2007 e março de 2008. Como critérios de seleção dos dois serviços em Natal/RN, assim como dos demais serviços participantes do projeto multicêntrico, foram considerados: tempo de funcionamento de, pelo menos, dez anos - sendo que a equipe de saúde em atividade funcionasse há, pelo menos, dois anos; volume de demanda igual ou maior que mil atendimentos/mês; presença de equipe multiprofissional; sensibilidade e disponibilidade da chefia para integrar a pesquisa.

Foram analisados diários de campo produzidos em observações etnográficas e depoimentos colhidos em entrevistas em profundidade com homens usuários de uma ou de outra dessas duas UBS. As observações foram realizadas por pesquisadores treinados, em dias e horários de funcionamento padrão dos serviços e no contexto das diversas atividades internas e externas às UBS, durante três meses, para cada um dos serviços.

Foram entrevistados 29 homens na UBS1 e 28 na UBS2, totalizando 57 entrevistas em Natal/RN. Durante o período de observação etnográfica e no contexto do atendimento aos usuários, foram realizados os convites das entrevistas. Mediante o aceite por parte dos usuários, era verificada a disponibilidade para a realização imediata, no próprio serviço, ou em data agendada segundo a conveniência de local, dia e horário para o usuário. Assim, parte das entrevistas foi realizada no serviço e parte na residência dos entrevistados; todas em ambiente privativo e sem a presença de terceiros.

No que diz respeito às temáticas investigadas na pesquisa multicêntrica, foram destacados, para a análise empreendida neste trabalho, os aspectos relativos à sexualidade masculina enquanto demandas e/ou questões apresentadas às UBS, e as respostas oferecidas.

O trajeto analítico-interpretativo foi orientado pela hermenêutica filosófica, segundo a qual a compreensão ocorre como interpretação, na qual está implicado o sujeito que interpreta, com seu 'modo de ser linguagem'. Assim, o encontro entre o sujeito que busca conhecimento e o sujeito que informa é melhor definido como um diálogo, em que, em vez de se alcançar o significado contido no fenômeno, negocia-se tal significado. O compreender e o interpretar consistem sempre em participar de um diálogo em que os horizontes se fundem (Ayres, 2008).

O tratamento dos dados teve o seguinte percurso: leitura do material proveniente das observações e entrevistas, com recorte dos trechos com questões relacionadas à sexualidade; leitura exaustiva dos trechos; identificação de assuntos e sentidos; interpretação e construção de uma síntese dos mesmos; articulação das questões encontradas com a literatura referente e a perspectiva teórica de gênero.

\title{
Homens e questões de sexualidade nas Unidades de Saúde
}

\author{
Pedro pedreiro penseiro esperando o trem [...] \\ esperando aumento para o mês que vem \\ esperando a festa, esperando a sorte \\ e a mulher de Pedro esperando um filho pra esperar também
}

(Chico Buarque, 1966)

Os homens entrevistados inserem-se num contexto de pobreza urbana. São moradores das redondezas das UBS pesquisadas, cujas localidades apresentam grande similaridade em termos de localização geográfica (não fazem parte da faixa litorânea e não apresentam conexões com o setor de turismo, uma das principais atividades econômicas da cidade) e de aspectos socioeconômicos (situam-se em bairros da periferia, que contam com pouca infraestrutura e que possuem altos índices de desemprego e violência).

A figura de Pedro Pedreiro, personagem de Chico Buarque, parece ser, grosso modo, uma boa caracterização para esses homens, aqui nomeados metaforicamente de Pedro4: homens simples, em arranjos familiares tradicionais e com poucas perspectivas de melhora de vida. O Quadro 1 detalha alguns aspectos sociodemográficos dos usuários. 
${ }^{4}$ Os homens entrevistados serão todos identificados como Pedro, mas diferenciados pelas iniciais de seu nome. Ex.: Pedro RS.
Quadro 1. Caracterização sociodemográfica dos homens entrevistados

\begin{tabular}{|c|c|c|c|c|}
\hline \multirow{2}{*}{$\begin{array}{c}\text { Características } \\
\text { sociodemográficas }\end{array}$} & \multicolumn{4}{|c|}{ Quantidade de homens por grupo etário } \\
\hline & $\begin{array}{c}16 \text { a } 25 \text { anos } \\
(n=17)\end{array}$ & $\begin{array}{c}26 \text { a } 45 \text { anos } \\
(n=20)\end{array}$ & $\begin{array}{c}46 \text { a } 60 \text { anos } \\
(n=20)\end{array}$ & $\begin{array}{c}\text { Total } \\
(n=57)\end{array}$ \\
\hline \multicolumn{5}{|l|}{ Raça/cor (autorreferida) } \\
\hline Branco & 8 & 6 & 4 & $18(36,6 \%)$ \\
\hline Pardo & 1 & 11 & 13 & $25(43,8 \%)$ \\
\hline Negro & 8 & 0 & 1 & $9(15,8 \%)$ \\
\hline Sem informação & 0 & 3 & 2 & $5(8,8 \%)$ \\
\hline \multicolumn{5}{|l|}{ Estado civil } \\
\hline Casado/união estável & 6 & 12 & 18 & $36(63,1 \%)$ \\
\hline Solteiro & 11 & 6 & 1 & $18(31,6 \%)$ \\
\hline Separado/divorciado & 0 & 2 & 1 & $3(5,3 \%)$ \\
\hline \multicolumn{5}{|l|}{ Posição na família } \\
\hline Chefe & 5 & 13 & 18 & $36(63,1 \%)$ \\
\hline Filho/neto & 11 & 5 & 0 & $16(28,1 \%)$ \\
\hline Mora só & 0 & 1 & 1 & $2(3,5 \%)$ \\
\hline Sem informação & 1 & 1 & 1 & $3(5,3 \%)$ \\
\hline \multicolumn{5}{|l|}{ Escolaridade } \\
\hline Analfabeto & 0 & 0 & 5 & $5(8,8 \%)$ \\
\hline Alfabetizado/Ensino Primário & 1 & 0 & 3 & $4(7,9 \%)$ \\
\hline Fundamental incompleto & 8 & 5 & 3 & $16(27,1 \%)$ \\
\hline Fundamental completo & 1 & 1 & 1 & $3(5,3 \%)$ \\
\hline Ensino Médio incompleto & 6 & 4 & 1 & $11(19,3 \%)$ \\
\hline Ensino Médio completo & 1 & 5 & 3 & $9(15,8 \%)$ \\
\hline Ensino Superior incompleto & 0 & 1 & 1 & $2(3,5 \%)$ \\
\hline Ensino Superior completo & 0 & 1 & 0 & $1(1,7 \%)$ \\
\hline Sem informação & 0 & 3 & 3 & $6(10,5 \%)$ \\
\hline \multicolumn{5}{|l|}{ Trabalho } \\
\hline Empregado/autônomo & 6 & 15 & 12 & $33(57,9 \%)$ \\
\hline Aposentado/licença médica & 0 & 0 & 6 & $6(10,5 \%)$ \\
\hline Desempregado & 2 & 5 & 1 & $8(14,0 \%)$ \\
\hline Estudante & 8 & 0 & 0 & $8(14,0 \%)$ \\
\hline Sem informação & 1 & 0 & 1 & $2(3,5 \%)$ \\
\hline \multicolumn{5}{|l|}{ Renda familiar } \\
\hline Até $\mathrm{R} \$ 500$ & 7 & 5 & 6 & $18(31,6 \%)$ \\
\hline $\mathrm{R} \$ 501$ a 1.000 & 6 & 8 & 5 & $19(33,3 \%)$ \\
\hline $\mathrm{R} \$ 1.001$ a 1.500 & 2 & 3 & 5 & $10(17,5 \%)$ \\
\hline Acima de $R \$ 1.500$ & 1 & 0 & 2 & $3(5,3 \%)$ \\
\hline Sem informação & 1 & 4 & 2 & $7(12,3 \%)$ \\
\hline
\end{tabular}

As UBS pesquisadas funcionam nos moldes da ESF, que destina-se a assistir, por meio de atividades internas e externas, os moradores da região pela qual cada unidade tem responsabilidade sanitária (Brasil, 2007). Ambas funcionam no horário das $7 \mathrm{~h} 30 \mathrm{~min}$ às $11 \mathrm{~h} 30 \mathrm{~min}$ e das $13 \mathrm{~h} 30 \mathrm{~min}$ às $16 \mathrm{~h} 30 \mathrm{~min}$. Na ocasião da pesquisa, a UBS1 dispunha de três equipes de Saúde da Família, e a UBS2, de duas. Além dos profissionais nucleares - médico/a, enfermeira, dentista, técnicas de enfermagem, agentes comunitários/as de saúde e auxiliar de consultório dentário -, a UBS1 contava com nutricionista e técnico em exames laboratoriais; a UBS2, com psicóloga, assistência social e fisioterapeutas.

Em relação ao espaço físico, as duas UBS dispunham de instalações suficientes para prestar assistência, havendo salas individuais para os atendimentos, exames e procedimentos, e áreas coletivas, como sala de espera, recepção e locais para reuniões e atividades educativas, além de copa e lugar destinado à esterilização de materiais. 
Tomando mais propriamente as questões em torno da sexualidade, observa-se que a estrutura organizacional das UBS reflete a atenção desigual dada a homens e mulheres nesses serviços. $A$ abordagem à sexualidade dos usuários e das usuárias acontece de forma bastante diferente, o que permite a referência a uma abordagem à sexualidade masculina, em distinção a uma feminina, como mostra a observação a seguir:

A abordagem à saúde sexual na UBS acontece, em parte, vinculada às atividades de planejamento familiar ou à saúde da mulher. O cuidado com a prevenção das IST acaba por ser uma extensão das consultas em que as usuárias tratam de reprodução ou fazem exames ginecológicos. O tema chega aos homens, portanto, com menor frequência e dissociado do viés reprodutivo, em consultas variadas em que alguma demanda nesse campo surja. (Diário de campo, UBS1)

A sexualidade masculina é abordada de forma pouco sistemática, não dispondo de um espaço demarcado na agenda de programas dos serviços (como acontece com a sexualidade feminina), e encontra, portanto, menos vias para ser inserida na discussão e intervenção em saúde. Dessa maneira, ela se apresenta de forma dispersa, podendo ser encontrada em meio a questões, queixas ou demandas que aparecem em diferentes momentos da assistência e se concentram em três temas, que serão discutidos a seguir.

\section{Infecções Sexualmente Transmissíveis}

A abordagem das IST aponta uma contradição entre a perspectiva dos homens usuários e a dos profissionais das UBS. De um lado, os primeiros acreditam tratar-se de um dos mais frequentes, senão o principal problema de saúde que acomete os homens. Ademais, acreditam que, entre eles, a incidência de IST é maior do que entre as mulheres.

"\{Quais são os principais problemas de saúde dos homens? As coisas das quais eles mais se queixam?\} O que eu vejo de amigos, de pessoas próximas é questão de ter doença sexualmente transmissível. Às vezes, eles ficam até mais vulneráveis do que as mulheres. Aqui no bairro teve uma época que teve bastante casos desse tipo, porque eles às vezes não se cuidam, né?, de usar preservativo, esse tipo de coisa". (Pedro GP, 28 anos)

Reproduz-se, assim, uma associação entre homens e IST, também encontrada na literatura, e que se sustenta na maior participação dos homens nos perfis epidemiológicos das IST. Essa participação se destaca no caso da aids, cujas notificações no Brasil revelam que, historicamente, houve uma predominância dos homens em relação às mulheres (Gomes, 2008).

Uma vez que vários usuários se identificam como alvo de IST, seria esperado, na assistência prestada a eles pelos serviços, um número considerável de atendimentos motivados por esse problema de saúde. Todavia, além de as UBS não enfatizarem esse problema como um foco de atuação, os profissionais não Ihe atribuem grandes dimensões, inferindo, pelos poucos casos que chegam aos serviços, que há uma baixa incidência, sobretudo entre os homens.

Os casos citados pelos profissionais se tratam, segundo eles, de quadros simples: infecções por gardnerella, tricomoníase, candidíase, sífilis, etc. Alguns foram diagnosticados nos exames preventivos ginecológicos, outros em outras consultas de praxe, em que os próprios usuários apontaram os sinais da doença. [...] A maioria dos atendimentos em saúde sexual é realizada com mulheres. [...] As usuárias são advertidas da necessidade da participação de seus maridos no tratamento; no entanto, alertam que eles se recusam a ir à unidade com esse fim. Dessa forma, o tratamento para o casal é orientado à mulher, que é incumbida de repassar para o companheiro. A enfermeira dificilmente tem informações a respeito da realização do tratamento pelo homem. (Diário de campo, UBS1) 
Nesse sentido, é oportuno resgatar o posicionamento do Ministério da Saúde (Brasil, 2010), ao reconhecer que, a despeito de uma aparente simplicidade no lidar com as IST, trata-se, ainda hoje, de um grave problema de saúde pública, por sua magnitude, pela dificuldade de as pessoas identificarem seus sintomas e, sobretudo, por serem grandes facilitadores da transmissão do HIV.

Considerando-se que a maioria dos casos de IST referidos pelos profissionais foi identificada entre as mulheres nos atendimentos ginecológicos, é possível perceber que a suposta baixa incidência desses agravos entre os homens está vinculada ao direcionamento da assistência para a atenção à sexualidade feminina. A detecção de IST neles costuma partir apenas de sua própria iniciativa em procurar os serviços com esse fim ou de uma abordagem indireta dos profissionais, tendo as parceiras como mediadoras.

Adicionalmente, a abordagem observada nos serviços dirige-se apenas à doença em si e a seu tratamento. As questões que a cerceiam, os significados atribuídos pelos sujeitos, seus receios e dúvidas não são contemplados pela atuação profissional; parecem não caber na assistência oferecida, ancorada na perspectiva da medicalização.

De modo particular, os casos de IST em homens, quando apresentados, foram encaminhados a outros serviços para realização do tratamento. Nesse sentido, as IST dos homens (ao contrário das que acometem as mulheres) são tratadas como um problema de alçada da assistência especializada, encontrando pouco espaço e atenção nos serviços da APS.

Contrárias a essa realidade, as diretrizes da Política Nacional de DST/AIDS (Brasil, 1999) preconizam que o diagnóstico e tratamento das IST devem ser oferecidos nos vários níveis de atenção do SUS. Embora seja prevista a implementação de unidades de referência em UBS selecionadas pelas coordenações estaduais e municipais, os profissionais da APS, ainda que não especialistas, estão habilitados a realizar diagnóstico por abordagem sindrômica, assim como tratar as doenças e orientar usuários/as a esse respeito.

O encaminhamento a serviços de referência implica tornar mais longo o caminho que o usuário deve percorrer até chegar ao tratamento, tanto pela necessidade de ir a outro serviço (e enfrentar novas dificuldades, como filas, esperas, distância) quanto pelas próprias dificuldades de encaminhamento, como mostra o exemplo:

\begin{abstract}
"Eu acho que foi da primeira vez que eu tive [uma IST], eu tive uma relação sexual, aí eu falei com a doutora, não sei nem quem foi ali, ela deu as informações corretas, eu falei o que era, ela não pediu pra ver. \{Não pediu?\} É. Ela disse que esse problema não era com ela, era com o médico de pele, um negócio assim, ela me encaminhou. [...] Ela passou um remédio. “Olhe, tome esse remédio aqui, mas é só pra aliviar a dor - um negócio assim - porque esse não é um remédio pra sarar. Assim, eu não entendo, vou encaminhar você para o médico de pele." Aí, ela pegou e encaminhou, mas demorou [...] para o encaminhamento chegar. [...] Demorou um mês, três semanas, por aí". (Pedro RS, 18 anos)
\end{abstract}

\title{
Prevenção ao câncer de próstata
}

O câncer de próstata consiste em um dos problemas mais lembrados na discussão da saúde dos homens. A popularidade desse agravo pode ser verificada no discurso dos próprios usuários das UBS:

"Tem os problemas da próstata aí, que só dá em homem, mas o resto das doenças eu acho que é pra homem e pra mulher, não é?". (Pedro SR, 62 anos)

Esse problema de saúde é acompanhado por uma tensão proveniente dos sentidos acionados pelo formato de um dos procedimentos utilizados na prevenção, o toque retal. Por envolver a exposição e o contato com as nádegas dos usuários homens, esse procedimento assume a conotação de ameaça à masculinidade.

Dado que a região das nádegas iguala o homem à mulher e, portanto, pode feminilizá-lo, entra, no roteiro da conduta orientada pelo modelo hegemônico de masculinidade, a necessidade de proteger 
essa região do toque e, mais ainda, da penetração. Na cultura brasileira, a penetração consiste num elemento fundamental para a construção simbólica de gênero, uma vez que o masculino é definido como ativo, insertivo, o que penetra (DaMatta, 1997).

Pela conotação sexual que adquire e aciona, a prevenção do câncer de próstata torna-se assunto relacionado à sexualidade masculina pelo viés da ameaça à masculinidade. Daí, o toque retal ou a simples alusão a ele serem, com frequência, acompanhados de constrangimento ou vergonha, inclusive por parte dos homens mais jovens, que estão longe de serem indicados à realização desse procedimento. Nessa direção, se dá a resistência ou a recusa de alguns homens a se submeterem ao exame.

“Aquele... Como é que é? Agora me esqueci... Da próstata, como é? Só esse mesmo. Eu acho que eu não ficaria à vontade não. [...] Nem com médico, nem médica, nem com nada. [...] Rapaz (risos), eu digo a você que eu não iria não. Eu acho que não". (Pedro LN, 18 anos)

De acordo com Gomes (2003), vários pontos de tensão podem estar envolvidos no toque retal (incômodo com a penetração, receio de dor física e simbólica, de ter ereção, de ficar descontraído), e os profissionais, por partilharem do imaginário social, também podem ficar constrangidos e inseguros diante da possibilidade de medos e fantasias dos usuários.

A racionalidade médica, na qual não cabem tais interpretações, de um lado, fundamenta a neutralidade como característica do olhar e da postura dos profissionais, neutralidade essa que tem tornado possível a realização de procedimentos como o toque retal, a despeito das tensões e resistências emergentes. De outro lado, sustenta a pouca importância dada aos sentidos que esse procedimento adquire frente à construção das masculinidades, o que pode ser visto, como lembra Gomes (2003), na escassez de estudos que se detêm em tal reflexão, e no despreparo de profissionais que realizam esse procedimento e planejam as campanhas de prevenção.

Comumente, essa racionalidade se impõe aos usuários, que a adotam como verdade sobre a relação com o profissional e, em especial, sobre o contato físico. Dessa forma, nota-se a conformação de vários homens ao procedimento do toque retal, motivada, muitas vezes, pelo receio de agravamento da saúde:

“Eu tô querendo fazer a marcação pra o exame da próstata, que eu nunca fiz. Tô com 54 anos e não fiz ainda. [...] O médico que diz, aquele da televisão, diz que com 40 anos o cara tem que fazer. E tá matando muito homem a próstata, né? Aí quero marcar um para fazer, vou pedir o encaminhamento, se Deus quiser". (Pedro JO, 54 anos)

Nesse sentido, a entrada em cena da prevenção do câncer de próstata pode representar também um avanço na medicalização do corpo e da vida sexual dos homens.

Paralelo a isso, a reação dos usuários homens ao possível processo de medicalização, especialmente ao problematizarem esse procedimento, toma por base o modelo tradicional de masculinidade.

“ $\{$ E você já imaginou assim como seria fazer esse exame? [...]\} Rapaz, eu nunca tive essa experiência não e também eu tô até desinformado; eu questiono, com esse sentido, [...] de, por exemplo, ser um toque e tal, o médico vem, chega e fica observando ali. Então, eu digo o seguinte: não estamos no tempo da pedra lascada, nós estamos hoje num mundo informatizado, talvez tenha um tipo de aparelho que chegue e já resolva esse problema sem tá precisando dessa coisa velha, antiga. [...] Tem esses incômodos, os comentários, brincadeira, lorota, aquelas coisas bobas, né? [...] \{Mas o que você acha desse exame em relação à masculinidade? Ao homem fazer um exame desse tipo?\} Rapaz, se a gente for olhar o lado profissional, a gente vai se sentir bem; mas, se for pro lado da sua imagem e tal, é chato. [...] Rapaz, o cara foi lá e fez assim, assim... Se um cara passar assim ao menos a mão no traseiro de outro, já leva porrada; mas no exame é um profissional que tá ali, ele vai cuidar da saúde, pra ele é normal". (Pedro NP, 45 anos) 
Ao questionar e sugerir uma intervenção informatizada, o usuário revela a tentativa de proteger sua masculinidade no âmbito social, haja vista que tal atributo é sempre atualizado no empírico, por meio da validação de outros homens (Silva, 2007; DaMatta, 1997). Ele parece recorrer ao argumento da neutralidade e normalidade da intervenção profissional para seu próprio convencimento quanto à necessidade de se submeter ao procedimento. No entanto, proteger o ideal de masculinidade em certos momentos, para alguns, pode ser mais importante do que se cuidar.

\section{Problemas relativos à ereção}

No título de 'problemas relativos à ereção', agrupam-se as denominações de disfunção sexual ou impotência sexual, e as referências feitas, explícita ou implicitamente, por meio de termos descritivos ou metafóricos, à dificuldade ou impossibilidade de ter ereção.

Esses problemas foram largamente citados pelos usuários ao se referirem a questões de saúde que afetam os homens, seja como vivência do problema ou como situação hipotética.

Em qualquer desses casos, trata-se de uma situação que adquire significados atrelados à(s) masculinidade(s). Uma vez que a 'potência' e a atividade sexual (com penetração) são símbolos da virilidade, a 'impotência', representada por esses problemas, surge como contraponto (Gomes, 2008). Considerando que esses problemas se inscrevem, predominantemente, nos relatos do segmento acima dos 45 anos, tal condição assume ainda o sentido de falência do organismo.

\footnotetext{
"Mas a queixa maior que eu acho é ficar velho e acabar a potência, o homem fica mais fragilizado, é isso aí. [...] Tem homem que toma Viagra, eu nunca tomei. Pra mim é isso, se a minha potência acabou, então é isso, acabou. Tudo tem começo e fim. Eu não vou inventar essas coisas não". (Pedro FR, 68 anos)
}

Imersos em vários sentidos e significados, os problemas relativos à ereção encontram, assim como as IST, uma resistência maior que a habitual a serem levados ao serviço. Alguns homens, se não permanecem em silêncio, procuram, para lidar com esse problema, caminhos que desviem do serviço de saúde e, em especial, de profissionais mulheres.

Nas observações realizadas, esses problemas, quando surgiram como queixa ou temática no contexto dos atendimentos, foram tratados de forma abreviada e superficial. A cena a seguir se refere à observação de uma consulta e ilustra a dificuldade tanto do médico quanto do usuário em abordar o assunto:

Na ocasião, o médico realizava um atendimento a um senhor de 59 anos que sofre de hipertensão arterial:

- O senhor toma esse medicamento há algum tempo já. O senhor se dá bem com ele?

- Sim. A pressão baixou, não foi?

- Mas baixou pouco. Era para baixar mais. E me diga uma coisa: o senhor é casado, não é?

[Paciente confirma com a cabeça] Como estão as relações com sua esposa? Está tudo certo?

- Assim, o senhor tem que ver que eu não sou mais um jovem...

[Médico interrompe] - Veja bem, esse medicamento que o senhor está usando, o propanolol, é bom, mas a gente geralmente não passa para homem porque ele diminui a libido. Por isso que eu perguntei ao senhor como estavam as relações.

- Não. Está tudo bem. Não afetou nada não.

- Bom, se o senhor está me dizendo que está tudo bem...

- Está sim. Você vai ver, na próxima consulta, minha pressão vai ter baixado mais.

- Ok. Mas vamos ficar de olho. Qualquer coisa, a gente troca a medicação. (Diário de campo, UBS1)

Nesse atendimento, além de o único aspecto da sexualidade do usuário enfatizado ter sido a suspeita de 'diminuição de libido', a abordagem do profissional considerou apenas a possibilidade de 
interação do medicamento com a atividade sexual, como se esta estivesse desligada de outros fatores como o estágio de vida do usuário, sua relação conjugal, suas condições emocionais, sociais etc.

Em revisão da perspectiva teórica e das intervenções no tratamento da 'disfunção erétil', Winton (2000) ressalta o desenvolvimento do modelo biomédico que, focado nas estruturas biológicas e na interação entre a biologia e química no corpo, torna-se cada vez mais o paradigma dominante no campo das 'disfunções sexuais masculinas'. De forma semelhante, outros autores (Potts et al., 2006; Aquino, 2005) discutem o lugar dessas disfunções na medicalização do corpo e da vida sexual dos homens.

É possível inferir que a não-adesão ou os questionamentos de alguns usuários ao tratamento prescrito para os problemas relativos à ereção podem representar uma resistência à possível medicalização, conforme ilustra a fala que o usuário, atendido na consulta descrita acima, dirige ao pesquisador após deixarem a sala do médico:

Você viu? Ele achava que tinha problema na medicação. Mas eu vou the contar. Sabe o que foi? Eu fiz estripulia, bebi e comi umas comidas salgadas, por isso a pressão deu alta. E outra, eu não vou dizer a ele, minha mulher é velha já, mas eu pego umas negas e não tenho problema nenhum. (Diário de campo, UBS1)

O usuário expôs informações que não contou ao médico, possivelmente devido à falta de disponibilidade do profissional para acolher as demandas que fogem à lógica de intervenção da biomedicina. Não contar as 'estripulias' pode ser reflexo do receio de compartilhar comportamentos que, embora significativos para o seu bem viver, poderiam ser condenados por uma postura normatizadora do médico.

Considerando o parâmetro da biomedicina, a sexualidade masculina tende a ser abordada como função sexual, da qual o dado mais objetivo é a ereção, que acaba por ser um resumo ou uma tradução da funcionalidade sexual do homem. Nesse sentido, os problemas relativos a ela assumem o lugar de disfunção, como fica óbvio no termo consagrado atualmente na nomenclatura científica predominante, que toma a 'diversidade' como 'disfunção' (Potts et al., 2006). Essa perspectiva aparece em outras consultas observadas, de modo a direcionar a conversa acerca da sexualidade pela lógica da fisiopatologia:

A médica salienta que a glicose está alta. Chama atenção para o perigo da diabetes e os possíveis prejuízos nos rins, olhos, extremidades, incluindo pênis. "Tô com problema nesses três mesmo", afirma Pedro IC. A médica pergunta ainda sobre como está sendo administrada a medicação. Ele informa que nem sempre toma a mesma dosagem, às vezes aumenta, às vezes diminui. Ela ressalta que se deve tomar os medicamentos "religiosamente". O usuário argumenta que determinado remédio deixa-o "morto", sem poder ter relações sexuais. Pergunta se não há um jeito de tomar remédio e não ficar impotente. A médica explica sobre o excesso de glicose, diabetes, hipertensão e as consequências para a função sexual. Segundo ela, "todo homem vai ter impotência." [...] Orienta sobre realizar atividades físicas, fazer dieta, uso de medicamentos, ficar do lado de quem gosta. Pedro IC relata novamente sua demissão e o fato de ultimamente estar nervoso por isso, chegando a tomar três diazepans por dia. "Isso ai acaba com aquela função, viu?" Ressalta a médica. Explica sobre o uso de benzodiazepínicos. (Diário de campo, UBS2)

É interessante notar que a abordagem que reduz a saúde sexual ao funcionamento erétil do pênis deixa de problematizar a ereção como condição (in)dispensável ao exercício da sexualidade. Tal problematização poderia ampliar a discussão acerca das práticas, ainda centrada em certa hierarquia moral que coloca, no topo, a penetração vaginal e, como clímax, a ejaculação masculina (Villela, Arilha, 2003). Perde-se a oportunidade de questionar a centralidade dessa forma hegemônica de fazer sexo e contemplar possibilidades alternativas.

Adicionalmente, a abordagem descrita - feita a partir da lógica da medicalização e, em especial, da interação de medicamentos ou de efeitos secundários de outras patologias - não vislumbrou 
tratamentos possíveis para o problema apresentado, senão a intervenção nesses supostos agentes causadores.

Na direção contrária, Levine (2000) defende que, devido à sua grande influência na qualidade de vida dos homens acometidos (afetando a autoestima, a autoimagem, produzindo aumento de ansiedade, depressão e dificuldade nas relações), e por se apresentarem, também, como indicativos ou sintomas de outras doenças (como as cardiovasculares, por exemplo), os profissionais do 'Primary Care' deveriam concentrar maior atenção nas questões relativas à saúde sexual dos usuários nos exames físicos de rotina e no levantamento da história pessoal. Embora tal proposição tenha sido apontada para o contexto estadunidense, tem a mesma relevância para a APS no Brasil. Nesse sentido, a abordagem de problemas relativos à ereção nas UBS pode produzir uma atenção mais integral aos usuários, uma vez que permite articular a assistência ou prevenção desses problemas ao acompanhamento de outros com quais eles podem estar relacionados, como a hipertensão arterial, tratada prioritariamente nos serviços da APS.

\section{Considerações finais}

Diante do percurso realizado, é possível pensar que, pela íntima relação com a construção das masculinidades, a sexualidade masculina pode configurar uma via de acesso às representações dos homens a respeito do próprio corpo e da própria saúde, abrindo um possível caminho para a aproximação entre eles e os serviços.

O que se observa nos serviços, no entanto, é uma abordagem superficial, abreviada e ancorada no parâmetro da medicalização, de modo que a sexualidade só cabe nas discussões e intervenções profissionais (e, por repetição, na queixa dos usuários) se estiver na lógica da fisiopatologia. Nesse formato, a atuação dos profissionais e a estrutura organizacional dos serviços não têm dado conta de assistir os usuários (e, certamente, as usuárias) em suas necessidades em saúde sexual. Isso implica acrescentar, à vulnerabilidade dos indivíduos ao adoecimento nos níveis individual e social, fatores que os vulnerabilizam no âmbito programático (Ayres et al., 2006) - provenientes das políticas de saúde, do pouco espaço e suporte oferecidos nos serviços para lidar com questões relativas à sexualidade que, juntos, coadunam para a não-efetivação dos direitos sexuais.

Comparado à medicalização do corpo e da vida sexual das mulheres, já bem sedimentada ao longo de mais de dois séculos nas práticas em saúde (Vieira, 2002), o processo equivalente com o corpo e a sexualidade dos homens começa a ser sentido nos últimos anos (Gomes, 2008; Aquino, 2005). Da mesma forma, a reação à medicalização já tem história no caso delas. No caso dos homens, a reação se movimenta ainda, construindo os argumentos e buscando reconhecimento.

É óbvio que o atraso da inserção dos homens no processo de medicalização está atrelado à posição social de vantagem que historicamente ocuparam em relação às mulheres. Isso não justifica que a construção de uma equidade de gênero seja buscada por meio do 'desempoderamento' dos homens diante da medicalização. Isso não seria equivalente a empoderar as mulheres. Como defendem Carrara et al. (2009), destituir os homens da posição historicamente construída em nome de uma sujeição dos mesmos às normas da medicina é uma questão de exercício do poder médico sobre os homens.

Alguns homens têm incorporado o discurso médico e se sujeitado a suas determinações. Nesse sentido, é importante reconhecer que os homens, a despeito das barreiras à sua presença nos serviços, têm buscado atendimentos, têm demandado atenção. Isso fragiliza o argumento de que a prática do cuidado é exclusividade da 'natureza' ou da socialização feminina. Entretanto, é também importante notar que os homens, de alguma forma, têm resistido à medicalização, o que potencializa a necessidade de participação desses sujeitos na construção da assistência oferecida.

É interessante lembrar que o próprio termo saúde sexual esteve, inicialmente, atrelado à noção de sexualidade (inscrita no modelo biomédico), tendo sido utilizado como equivalente a esta. Apenas recentemente (2006), a Organização Mundial de Saúde ampliou a definição de saúde sexual para além da ideia de ausência de doenças, disfunções ou enfermidades, incorporando a referência aos direitos sexuais e a uma abordagem positiva da sexualidade e dos relacionamentos sexuais (Paiva et al., 2008). Essa nova perspectiva tanto pode subsidiar uma assistência mais integral à saúde e às questões sexuais, 
como pode fortalecer uma atuação de profissionais e usuários de serviços de saúde que caminhe na direção de resistir à medicalização.

Diante do cenário em que a leitura estereotipada de que os homens não se cuidam se depara com dados que mostram que o homem, ao buscar cuidado, muitas vezes não se submete à medicalização, talvez seja oportuno propor também uma abordagem positiva dos valores e características relativos ao masculino (e ao feminino), na qual as "insígnias de gênero possam ser usadas no sentido de crescimento mútuo" (Villela, 1999, p.212). Significa fazer uma aposta de que os atributos do masculino possam ser qualidades que ajudem homens e mulheres no cuidado à saúde, por exemplo, o saber e o poder sobre o sexo poderia facilitar o uso do preservativo.

Nesse sentido, a assunção de fragilidade e vulnerabilidade não precisa implicar submissão. Afinal, diante de um obstáculo à saúde, é preciso um re-conhecimento de uma fragilidade a ser cuidada, que não tem de ser oposta aos aspectos de assertividade do sujeito.

Nessa direção, os atributos de força e poder e a dificuldade de se sujeitar ao outro, característicos do padrão hegemônico de masculinidade, podem levar os homens a uma resistência à submissão à medicalização imposta nas questões de sexualidade, bem como podem provocar a construção de relações dialógicas entre profissionais e usuários homens. Mas, para isso, é imperativa a construção de outra racionalidade na saúde, a partir da qual o comprometimento com o sofrer do outro seja capaz de desviar o foco da doença para dar evidência à vida que se produz mesmo no adoecimento.

Se as dificuldades de reconhecimento dos carecimentos em torno da sexualidade estão presentes no desafio de entender-se com o outro, de acessar o que é obstáculo à vida para além da doença, para compreender o que os Pedros Pedreiros cuidam e/ou preservam em detrimento das possibilidades de adoecimento, é vital reconhecer a importância da dimensão relacional do trabalho em saúde e mudar os modos desse saber-fazer, incluindo sujeitos e coletivos.

\section{Colaboradores}

Thiago Félix Pinheiro redigiu a primeira versão do texto. Márcia Thereza Couto colaborou na delimitação do recorte do artigo e na segunda versão do texto. Geórgia Sibele Nogueira da Silva colaborou com comentários e sugestões na segunda versão do texto, e todos os autores trabalharam juntos na versão final do manuscrito.

\section{Referências}

AQUINO, E.M.L. Saúde do Homem: uma nova etapa da medicalização da sexualidade? Cienc. Saude Colet., v.10, n.1, p.19-22, 2005.

ARILHA, M.M. O masculino em conferências e programas das Nações Unidas: para uma crítica do discurso de gênero. 2005. Tese (Doutorado) - Faculdade de Saúde Pública, Universidade de São Paulo, São Paulo. 2005.

AYRES, J.R.C.M. Para comprender el sentido práctico de las acciones de salud: contribuiciones de la hermenêutica filosófica. Salud Colect., v.4, n.2, p.159-72, 2008.

AYRES, J.R.C.M. et al. Risco, vulnerabilidade e práticas de prevenção e promoção da saúde. In: CAMPOS, G.W.S. et al. (Orgs.). Tratado de saúde coletiva. São Paulo: Hucitec, 2006. p.375-417.

BOZON, M. Sociologia da sexualidade. Rio de Janeiro: Ed. FGV, 2004.

BRASIL. Ministério da Saúde. Departamento de DST, Aids e Hepatites Virais. 2010. Disponível em: <http://www.aids.gov.br>. Acesso em: 5 mar. 2010.

Ministério da Saúde. Secretaria de Atenção Básica. Política Nacional de atenção Básica. 4.ed. Brasília: SAB, 2007. 
BRASIL. Ministério da Saúde. Secretaria de Políticas Públicas de Saúde. Coordenação de DST e aids. Política Nacional de DST/AIDS: princípios, diretrizes e estratégias. Brasília: SPPS, 1999.

CARRARA, S.; RUSSO, J.A.; FARO, L. A política de atenção à saúde do homem no Brasil: os paradoxos da medicalização do corpo masculino. Physis, v.19, n.3, p.659-78, 2009.

CONNELL, R. La organización social de la masculinidad. In: VALDES, T.; OLAVARRÍA, J. (Orgs.). Masculinidad/es: poder y crisis. Santiago: Ediciones de las mujeres, 1997. v.24, p.31-48.

COURTENAY, W.H. Construction of masculinity and their influence on men's wellbeing: a theory of gender and health. Soc. Sci. Med., v.50, n.10, p.1385-401, 2000.

COUTO, M.T. et al. O homem na atenção primária à saúde: discutindo (in)visibilidade a partir da perspectiva de gênero. Interface - Comunic., Saude, Educ., v.14, n.33, p.257-70, 2010.

Saúde da população masculina na atenção primária: tendência histórica e representações sobre necessidades, acesso e uso de serviços em cidades de quatro estados do Brasil (RN, PE, RJ, SP). Relatório de pesquisa ao CNPq. São Paulo: Faculdade de Medicina, Universidade de São Paulo. 2009.

DAMATTA, R. "Tem pente aí?" Reflexões sobre a identidade masculina. In: CALDAS, D. (Org.). Homens. São Paulo: Senac, 1997. p.31-49.

FIGUEIREDO, W. Assistência à saúde dos homens: um desafio para os serviços de atenção primária. Cienc. Saude Colet., v.10, n.1, p.105-9, 2005.

FOUCAULT, M. História da sexualidade: a vontade de saber. Trad. Maria Thereza da Costa Albuquerque e J. A. Guilhon Albuquerque. 19.ed. Rio de Janeiro: Graal, 2007. 2v.

GOMES, R. Sexualidade masculina, gênero e saúde. Rio de Janeiro: Fiocruz, 2008.

Sexualidade masculina e saúde do homem: proposta para uma discussão. Cienc. Saude Colet., v.8, n.3, p.825-9, 2003.

GOMES, R.; NASCIMENTO, E.F. A produção do conhecimento da saúde pública sobre a relação homem-saúde: uma revisão bibliográfica. Cad. Saude Publica, v.22, n.5, p.901-11, 2006.

HOLLANDA, C.B. Pedro Pedreiro. In: Paulo: Gravadora RGE, 1966. faixa 6. $2 \min 38 \mathrm{~s}$

KIMMEL, M. La produccíon teórica sobre la masculinidad: nuevos aportes. Santiago: Ediciones de las mujeres, 1992. v.17, p.129-38.

LAURENTI, R.; MELLO JORGE, M.H.P.; GOTLIEB, S.L.D. Perfil epidemiológico da morbi-mortalidade masculina. Cienc. Saude Colet., v.10, n.1, p.35-46, 2005.

LEVINE, L.A. Diagnosis and treatment of erectile dysfunction. Am. J. Med., v.109, n.9, p.3S-12S, 2000.

PAIVA, V.; AYRES, J.R.M.C.; FRANÇA-JUNIOR, I. Saúde sexual e adolescência: expandindo os padrões normativos para a educação e o cuidado da sexualidade dos jovens. In: KOGA, D.; GANEV, E.; FÁVERO, E. (Orgs.). Cidades e questões sociais. São Paulo: Andross, 2008. p.157-84.

PEIRANO, M. A favor da etnografia. Rio de Janeiro: Relume Dumará, 1995.

PINHEIRO, R.S. et al. Gênero, morbidade, acesso e utilização de serviços de saúde no Brasil. Cienc. Saude Colet., v.7, n.4, p.687-707, 2002. 
PINHEIRO, T.F. A abordagem à sexualidade masculina na atenção primária à saúde: possibilidades e limites. 2010. Dissertação (Mestrado) - Faculdade de Medicina, Universidade de São Paulo, São Paulo. 2010.

PORTELLA, A.P. et al. Homens: sexualidades, direitos e construção da pessoa. Recife: SOS CORPO - Gênero e Cidadania, Instituto PAPAI, 2004.

POTTS, A. et al. 'Sex for life'? Male sexuality and ageing 'Sex for life'? Men's counterstories on 'erectile dysfunction', male sexuality and ageing. Sociol. Health Illn., v.28, n.3, p.306-29, 2006.

SCOTT, J. Gênero: uma categoria útil de análise histórica. Educação e realidade, v.20, n.2, p.71-99, 1995.

SILVA, G.S.N. Masculinidades e saúde do homem: a construção de vulnera(ha)bilidades. Rev. Bras. Sexual. Hum., v.18, n.2, p.431-40, 2007.

SOHN, A.M. O corpo sexuado. In: CORBIN, A.; COURTINE, J.J.; VIGARELLO, G. (Coords.). História do corpo: as mutações do olhar - o século XX. Petrópolis: Vozes, 2008. 3v, p.109-54.

TESSER, C.D. Medicalização social (I): o excessivo sucesso do epistemicídio moderno na saúde. Interface - Comunic., Saude, Educ., v.10, n.19, p.61-76, 2006.

VIEIRA, E.M. A medicalização do corpo feminino. Rio de Janeiro: Fiocruz, 2002.

VILLELA, W.V. Prevenção do HIV/Aids, gênero e sexualidade: um desafio para os serviços de saúde. In: BARBOSA, R.M.; PARKER, R. (Orgs.). Sexualidades pelo avesso: direitos, identidades e poder. Rio de Janeiro: IMS/UERJ, 1999. p.199-213.

VILLELA, W.V.; ARILHA, M. Sexualidade, gênero e direitos sexuais e reprodutivos. In: BERQUÓ, E. (Org.). Sexo e vida: panorama da saúde reprodutiva no Brasil. Campinas: Ed. da Unicamp, 2003. p.95-150.

WINTON, M.A. The medicalization of male sexual dysfunctions: an analysis of sex therapy journals. J. Sex Educ. Ther., v.25, n.4, p.231-9, 2000.

PINHEIRO, T.F.; COUTO, M.T.; NOGUEIRA DA SILVA, G.S. Cuestiones de la sexualidad masculina en la atención primaria de salud: género y medicalización. Interface Comunic., Saude, Educ., v.15, n.38, p.845-58, jul./set. 2011.

Ese artículo presenta una investigación etnográfica sobre el planteamiento de la sexualidad masculina en dos servicios de atención primaria de salud en Natal/Rio Grande do Norte, Brasil. Su objetivo es entender cómo se presenta la sexualidad de los hombres usuarios de los servicios en el contexto de la asistencia y cómo se afrontan las demandas que se configuran en ese contexto. En las entrevistas con los usuarios y observaciones del cotidiano de los servicios se destacan como principales problemas las infecciones de transmisión sexual, la prevención del cáncer de próstata y problemas relacionados con la erección. Se observa un planteamiento profesional superficial, abreviado y anclado en la medicalización. Aunque algunos usuarios incorporen el discurso médico y se sometan a la medicalización, es posible identificar señales de resistencia. Se discute cómo las marcas de género pueden provocar una construcción de relaciones dialógicas entre profesionales y usuarios hombres.

Palabras clave: Sexualidad masculina. Masculinidade. Medicalización. Atención primaria de salud. 